\title{
openheart Smokeless tobacco use and circulatory disease risk: a systematic review and meta-analysis
}

\author{
Brian L Rostron, Joanne T Chang, Gabriella M Anic, Manju Tanwar, \\ Cindy M Chang, Catherine G Corey
}

To cite: Rostron BL, Chang JT, Anic GM, et al. Smokeless tobacco use and circulatory disease risk: a systematic review and meta-analysis. Open Heart 2018;5:e000846. doi:10.1136/ openhrt-2018-000846

Received 2 May 2018

Revised 24 July 2018

Accepted 22 August 2018

Check for updates

(c) Author(s) (or their employer(s)) 2018. Re-use permitted under CC BY-NC. No commercial re-use. See rights and permissions. Published by BMJ.

Center for Tobacco Products, Food and Drug Administration, Silver Spring, Maryland, USA

Correspondence to Dr Brian L Rostron; brian. rostron@fda.hhs.gov

\section{ABSTRACT}

Objective Smokeless tobacco use is a public health issue throughout the world, but reviews and analyses of circulatory disease risks associated with smokeless tobacco use may be outdated or incomplete. This study provides a thorough and comprehensive review and meta-analysis of circulatory disease risks in high-income countries, including recently published study estimates. Methods We conducted a systematic review of studies of circulatory disease risks associated with smokeless tobacco use in Europe and North America that were identified from electronic databases and reference lists. Study estimates were extracted by region, smokeless tobacco use status, cigarette smoking status, and circulatory condition and combined in meta-analysis using a random-effects model. We used the Newcastle-0ttawa scale to assess study quality and risk of bias.

Results We identified 17 relevant cohort studies, two pooled analyses, five case-control studies and one cross-sectional analysis. We found increased risk of heart disease (relative risk (RR) $1.17,95 \% \mathrm{Cl} 1.09$ to 1.27) and stroke (RR $1.28,95 \% \mathrm{Cl} 1.01$ to 1.62) among US smokeless tobacco users compared with non-users. Increased circulatory disease risk was not observed among Swedish smokeless tobacco users.

Conclusion US smokeless tobacco users were found to have increased risk of heart disease and stroke.

\section{INTRODUCTION}

The health effects of smokeless tobacco use are of considerable research and public health interest. Globally, more than 300 million people use these products, many of them in low-income countries. ${ }^{1}$ In the USA, it has been estimated that smokeless tobacco use was responsible for approximately 1600 new cases of oral cancer, 500 new cases of pancreatic cancer and 200 new cases of oesophageal cancer in 2008. ${ }^{1}$ Although some types of smokeless tobacco have been found to be associated with circulatory conditions including heart disease and stroke, ${ }^{23}$ comprehensive reviews of this association in high-income countries may be out of date or limited by the number of study estimates they

\section{Key questions}

What is already known about this subject?

- Smokeless tobacco use is known to pose numerous health risks, but reviews and analyses of circulatory disease risks in high-income countries may be outdated or incomplete.

What does this study add?

- This study finds that US smokeless tobacco users have increased risks of heart disease and stroke compared with non-users, although it did not observe increased risk among Swedish smokeless users.

How might this impact on clinical practice?

- Practitioners should advise their patients who use smokeless tobacco products of the known health risks and provide advice on cessation.

identified. Moreover, disease burden calculations for smokeless tobacco in the USA are generally unavailable for these conditions.

Several reviews of smokeless tobacco use and circulatory disease risk have been conducted previously. Lee $^{2}$ reviewed 11 studies from Sweden and the USA in 2007 and found an association between smokeless tobacco use and increased heart disease risk based on eight studies, increased stroke risk based on five studies and increased overall circulatory disease risk based on three studies. Boffetta and Straif ${ }^{3}$ also identified 11 observational studies from Sweden and the USA in 2009 and found an association between smokeless tobacco use and increased risk of fatal myocardial infarction based on eight studies and increased risk of fatal stroke based on five studies. Zhang $e t a l^{4}$ identified eight studies from Asian countries, principally Bangladesh, India and Taiwan in 2010. They found increased cardiovascular and ischaemic heart disease risk based on six studies and increased cerebrovascular risk based on three studies for ever users of chewing substances with and without tobacco. 
Siddiqi et at reviewed 13 studies of heart disease and stroke risk from South Asia and Sweden in 2015 and did not observe increased risk in Swedish studies. They noted that the multicountry INTERHEART study with data from 52 countries found increased heart disease risk among smokeless tobacco users. Vidyasagaran et at reviewed 20 studies from South Asia, Sweden and the USA in 2016 and found increased mortality risk from ischaemic heart disease and stroke among ever smokeless tobacco users. Results varied by region, with a significant association for non-fatal ischaemic heart disease in Asian but not European studies. Sinha et al identified 16 studies of all-cause and cause-specific mortality risk from South Asia, Sweden and the USA in 2018. They found smokeless tobacco use to be associated with increased mortality risk for all causes as well as ischaemic heart disease and stroke. Gupta $e t a l^{8}$ reviewed 20 studies from South Asia, Iran, Sweden and the USA, also in 2018, and found an association between smokeless tobacco use and fatal coronary heart disease in Swedish studies and studies overall.

Several reviews of smokeless tobacco use and circulatory disease risks have thus been published, but these reviews have varied in terms of the geographical areas and smokeless tobacco products they covered, the studies they included and the findings they reported. In addition, new studies on this topic have been published. ${ }^{9-11}$ The aim of this study therefore is to produce an updated systematic review and meta-analysis of smokeless tobacco use and circulatory disease risks, specifically focusing on studies conducted among European and North American smokeless tobacco users. These regions were selected because products from these areas, such as chewing tobacco, moist snuff and snus, are commonly sold in the US market and thus regulated by the US Food and Drug Administration. Moreover, smokeless tobacco products from other areas such as South Asia and Africa can be quite different in terms of product characteristics and health risks from products sold in the USA. ${ }^{12}$ This review covers circulatory conditions including heart disease, stroke and other circulatory conditions.

\section{METHODS}

The study consisted of a systematic review and meta-analysis of studies of smokeless tobacco use and circulatory disease risk in Europe and North America that contained a quantitative relative risk estimate for users compared with non-users. The review and meta-analysis were conducted in accordance with PRISMA ${ }^{13}$ (Preferred Reporting Items for Systematic Reviews and Meta-Analyses) guidelines using a prespecified study protocol. Given that the study did not involve primary data collection or analysis, the study was considered exempt from human subjects committee review. In August 2017, we searched PubMed, EMBASE, Web of Science and Ebscohost databases for references that contained terms for both smokeless tobacco and circulatory conditions. The online supplementary appendix shows the relevant search terms for each database. Two reviewers (GMA and JTC) independently reviewed the titles and abstracts of these articles and identified relevant references for further review. Each reviewer then evaluated each reference for inclusion in the study. We searched for relevant unpublished studies by reviewing previous reviews and the reference lists of selected articles. Preliminary studies by two groups of researchers ${ }^{14-16}$ were identified in our search but were not included in the review because they have yet to be published. The rationale for their exclusion is explained in greater detail in the Discussion section. The reviewers then extracted relevant information from identified studies including study design, country, study size, smokeless tobacco type, and circulatory conditions or mortality outcomes. Because studies often report more than one estimate, specific estimates for each outcome from each study were extracted using the following order of preference lists: smokeless tobacco type (all, snuff or snus, chewing tobacco), smokeless tobacco use status (current or former, ever), cigarette smoking status (never, non-current, any smoking status), medical outcome (specific circulatory conditions such as heart disease or stroke, all circulatory conditions), outcome type (all cases, then fatal or non-fatal events for the type that has the greater number of cases) and adjustment for other risk factors (the most extensive adjustment available). Medical outcomes were categorised as ischaemic heart disease (conditions included in International Classification of Diseases (ICD)-9 410-414, sometimes characterised as myocardial infarction, coronary heart disease or cardiovascular disease in specific studies), stroke (ICD-9 430-438) and other circulatory conditions (the remainder of ICD-9 390-459). The quality of these studies was also assessed using the Newcastle-Ottawa scale, a standardised scale to assess the quality of non-randomised studies included in systematic reviews and meta-analyses. ${ }^{17}$ Studies were assigned a maximum of nine stars based on established criteria for the selection of study groups, the comparability of groups and the ascertainment of exposure for case-control studies and outcome for cohort studies. Additional information about the scale and its criteria are provided in online supplementary tables.

These estimates were then combined using meta-analysis with a random-effects model to produce summary relative risk estimates by country and outcome. Heterogeneity was assessed through $\chi^{2}$ tests of Cochran's $Q$ as well as the $\mathrm{I}^{2}$ statistic. Publication bias was assessed through funnel plots, although the number of studies by country and outcome was limited. Two pooled analyses have been published that combine individual-level data from eight Swedish cohort studies, some of which had previously produced relative risk estimates for heart disease and stroke. ${ }^{18} 19$ Estimates from the pooled analyses were included in the meta-analyses, and estimates from studies that were included in the pooled analyses were not, but the published studies are described in the summary tables. We also conducted sensitivity analyses omitting 


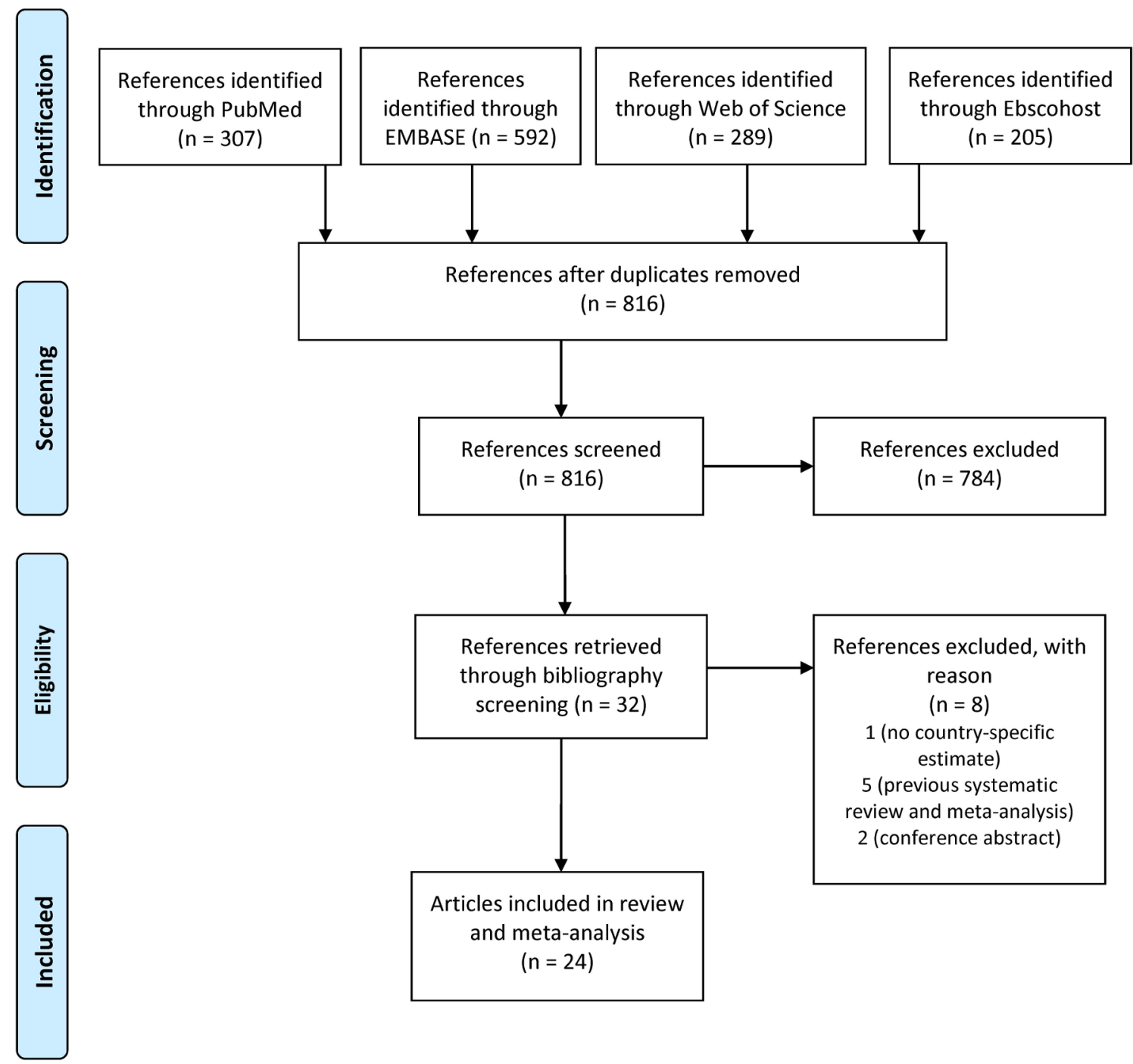

From: Moher D, Liberati A, Tetzlaff J, Altman DG, The PRISMA Group (2009). Preferred Reporting Items for Systematic Reviews and MetaAnalyses: The PRISMA Statement. PLoS Med 6(6): e1000097. doi:10.1371/journal.pmed1000097

For more information, visit www.prisma-statement.org.

Figure 1 Flow diagram for selection of studies for review.

the small number of estimates from case-control and cross-sectional studies. Differences in study estimates between countries for outcomes were assessed using random-effects meta-regression, although again the number of studies and study events limited the ability to detect statistically significant differences. Meta-analysis was conducted using Stata version 15.

\section{RESULTS}

A total of 816 unique references were found through searching electronic databases, and reviewers identified 32 of these references for further review. Figure 1 shows that five references were excluded as previous reviews, ${ }^{23-7}$ two references were excluded as abstracts of conference presentations ${ }^{1420}$ and one reference did not present country-specific relative risk estimates for smokeless tobacco use. ${ }^{21}$

Table 1 summarises the characteristics of 17 identified cohort studies that produced relevant risks estimates for smokeless tobacco use, 11 of which were conducted in Sweden ${ }^{22-32}$ and six in the USA. ${ }^{9}{ }^{10}{ }^{33-35}$ Results from the Construction Worker's study, Malmo study, Twin Registry study and MONICA study 222529 were included in two pooled analyses of data on acute myocardial infarction and stroke from eight cohort studies in Sweden. ${ }^{18} 19$ Table 2 presents the characteristics of five case-control studies from Sweden ${ }^{36-40}$ and one analysis of cross-sectional survey data from the USA. ${ }^{11}$ Four of the Swedish case-control studies ${ }^{36-39}$ were drawn from the MONICA cohort study, which was also included in the pooled analyses. Study quality was generally good, with 12 of the 17 
cohort studies, both of the pooled analyses, and three of the five case-control studies receiving at least seven stars on the Newcastle-Ottawa scale. Online supplementary table 1 and 2 provides detailed scores by study for each of the scale's criteria. Studies scored well on ascertainment of exposure, selection of controls or non-exposed cohort members, use of control variables for other risk factors and assessment of outcome. Most cohort studies did not provide adequate information about follow-up for study participants according to the scale's criteria, and a majority of case-control studies did not provide sufficient response rate information. Table 3 shows the relevant estimates that were extracted from each study as well as the other factors that were adjusted for in the analyses.

Table 4 and figure 2 present results from the meta-analyses. No increased risk of ischaemic heart disease or stroke was observed in Swedish studies among current or former snus users compared with non-users. An individual study found increased risk of hypertension among current snus users in Sweden. ${ }^{32}$ In the USA, current smokeless tobacco users had increased risk of heart disease (relative risk (RR) $1.17,95 \%$ CI 1.09 to 1.27) and stroke (RR 1.28, 95\% CI 1.01 to 1.62). These results remained consistent with the inclusion of studies of ever smokeless tobacco users. Similar results were also generally observed in studies that looked at heart disease and stroke together. In the one study that looked at circulatory risks for former smokers who had switched to smokeless tobacco at the time of or after they quit exclusive cigarette smoking compared with former smokers who had quit tobacco use entirely, higher risks were found for switchers for heart disease (RR 1.13, 95\% CI 1.00 to 1.29) and stroke (RR $1.24,95 \%$ CI 1.01 to 1.53 ). In most cases, heterogeneity across study estimates within country was limited, although differences were observed for estimates of stroke risk for US smokeless tobacco users $\left(\mathrm{I}^{2}=72.0 \%\right)$. Meta-analysis results from sensitivity analyses omitting estimates from case-control and cross-sectional studies were similar to results from the main analysis. Without estimates from case-control studies, the summary relative risk for ischaemic heart disease in Swedish studies was 1.05 (95\% CI 0.93 to 1.17) for current smokeless tobacco users and 0.81 (95\% CI 0.61 to 1.09) for former users compared with 1.04 (95\% CI 0.93 to 1.16 ) for current users and 0.85 (95\% CI 0.66 to 1.08) for former users in the main analysis. Meta-regression showed some evidence of differences between estimates by country, although the number of studies limited the ability to detect statistically significant differences. For example, for ischaemic heart disease the summary risk ratio of US to Swedish studies was 1.14 (95\% CI 0.90 to 1.43 ), and the proportion of between-study variance explained by country $\left(R^{2}\right)$ was $29.6 \%$.

\section{DISCUSSION}

This study represents a systematic review and meta-analysis of studies of smokeless tobacco use and circulatory disease risk in Europe and North America. It has identified 17 cohort studies, five case-control studies, one cross-sectional analysis and two pooled data analyses with relevant risk estimates, all of which were conducted in Sweden or the USA. Meta-analysis results did not show increased risk of heart disease or stroke among smokeless tobacco users in Sweden compared with non-users, but did show increased heart disease and stroke risk for US smokeless tobacco users. These US results were consistent for current smokeless tobacco users compared with never tobacco users and for former smokers who had switched to smokeless tobacco use compared with former smokers who had quit tobacco use entirely.

Several previous meta-analyses have been conducted on this topic, but this study includes more recent studies and provides updated estimates. For example, Lee ${ }^{2}$ reviewed studies of smokeless tobacco use and circulatory disease risk from Sweden and the USA in 2007 and Boffetta and Straif ${ }^{3}$ conducted a similar review in 2009. Both analyses identified mortality follow-up studies published by Accortt et $a p^{33}$ and Henley $e$ t $a l^{34}$ as the only relevant US studies available at that time. Subsequent reviews on this topic have either identified only these studies ${ }^{6-8}$ or no studies ${ }^{5}$ from the USA. Our study has included estimates from several additional US studies that uise data from sources such as the prospective, community-based Atherosclerosis Risk in Communities Study, ${ }^{10}$ the cross-sectional Behavioral Risk Factor Surveillance System survey of health behaviours and conditions, ${ }^{11}$ and the nationally representative National Longitudinal Mortality Study (NLMS), which links Tobacco Use Supplement to the Current Population Survey data to mortality follow-up. ${ }^{9}$

The observed differences in results from meta-analyses for Sweden and the USA are generally consistent with the more limited results from previous reviews, ${ }^{2}{ }^{3}$ but the consistency of results across studies for multiple conditions in the two countries is striking. The observed increased circulatory disease risk among US smokeless tobacco users may be the result of various factors in terms of product characteristics and behavioural use. US smokeless tobacco products are known to contain varying levels of numerous constituents including nicotine, tobacco-specific nitrosamines (TSNAs) such as the carcinogens NNN and NNK, anions such as nitrite, nitrate and chloride, polycyclic aromatic hydrocarbons such as benzo $[a]$ pyrene and volatile aldehydes such as formaldehyde. ${ }^{41}{ }^{42}$ They also vary in their concentrations of toxic metals such as arsenic, cadmium, chromium, nickel and lead. ${ }^{42}{ }^{43}$ Swedish snus products, in contrast, are subject to a quality control standard known as GothiaTek that sets maximum limits on product constituents including TSNAs, nitrite, benzo $[a]$ pyrene and metals. ${ }^{44}$ Studies have found that Swedish snus products generally have lower levels of various constituents including TSNAs such as NNN and NNK, anions such as nitrate and nitrite, and polycyclic aromatic hydrocarbons such as benzo $[a]$ pyrene compared with US conventional smokeless tobacco products. ${ }^{41} 42$ Specifically with regard to circulatory risks, Swedish snus has been found 


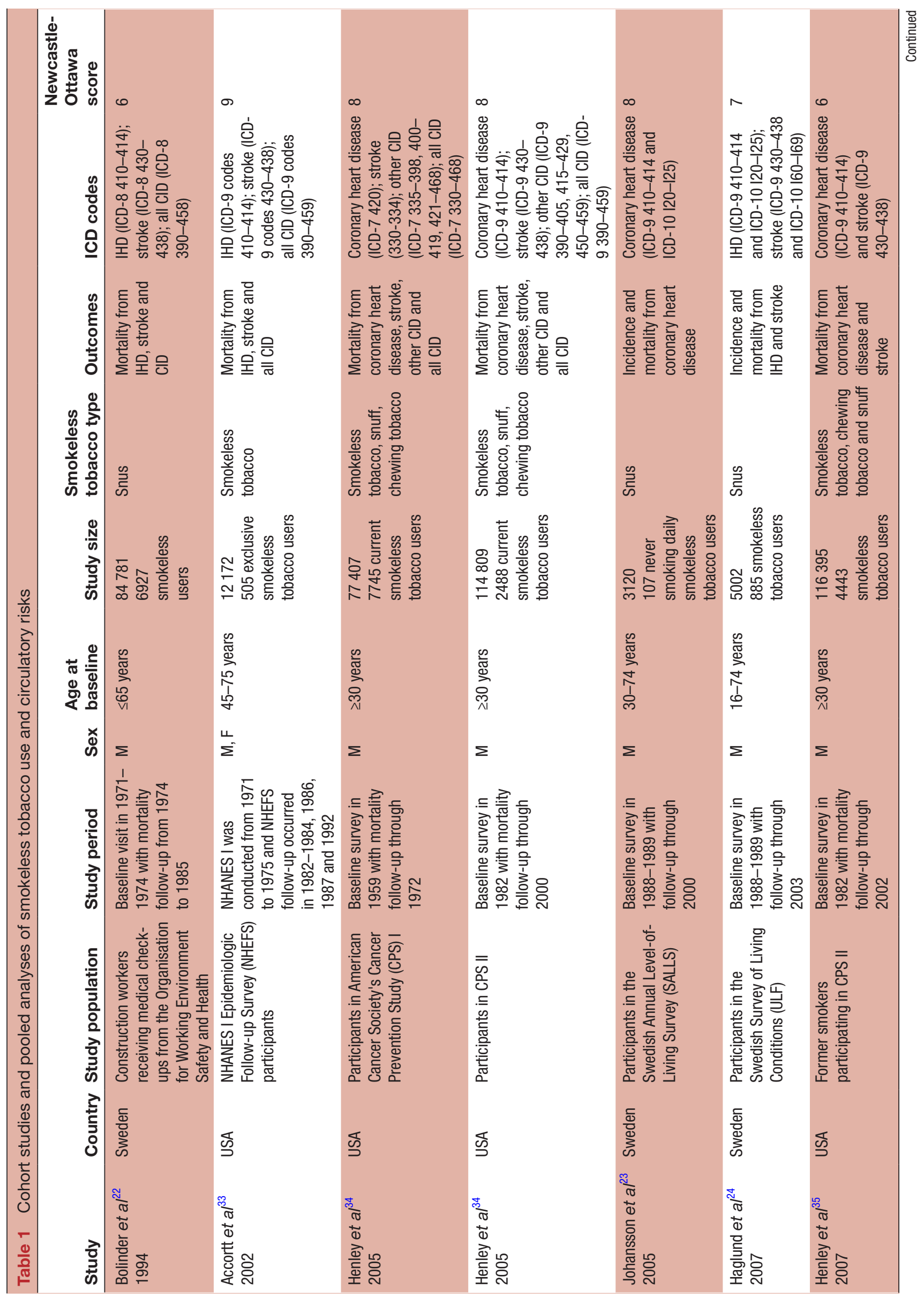




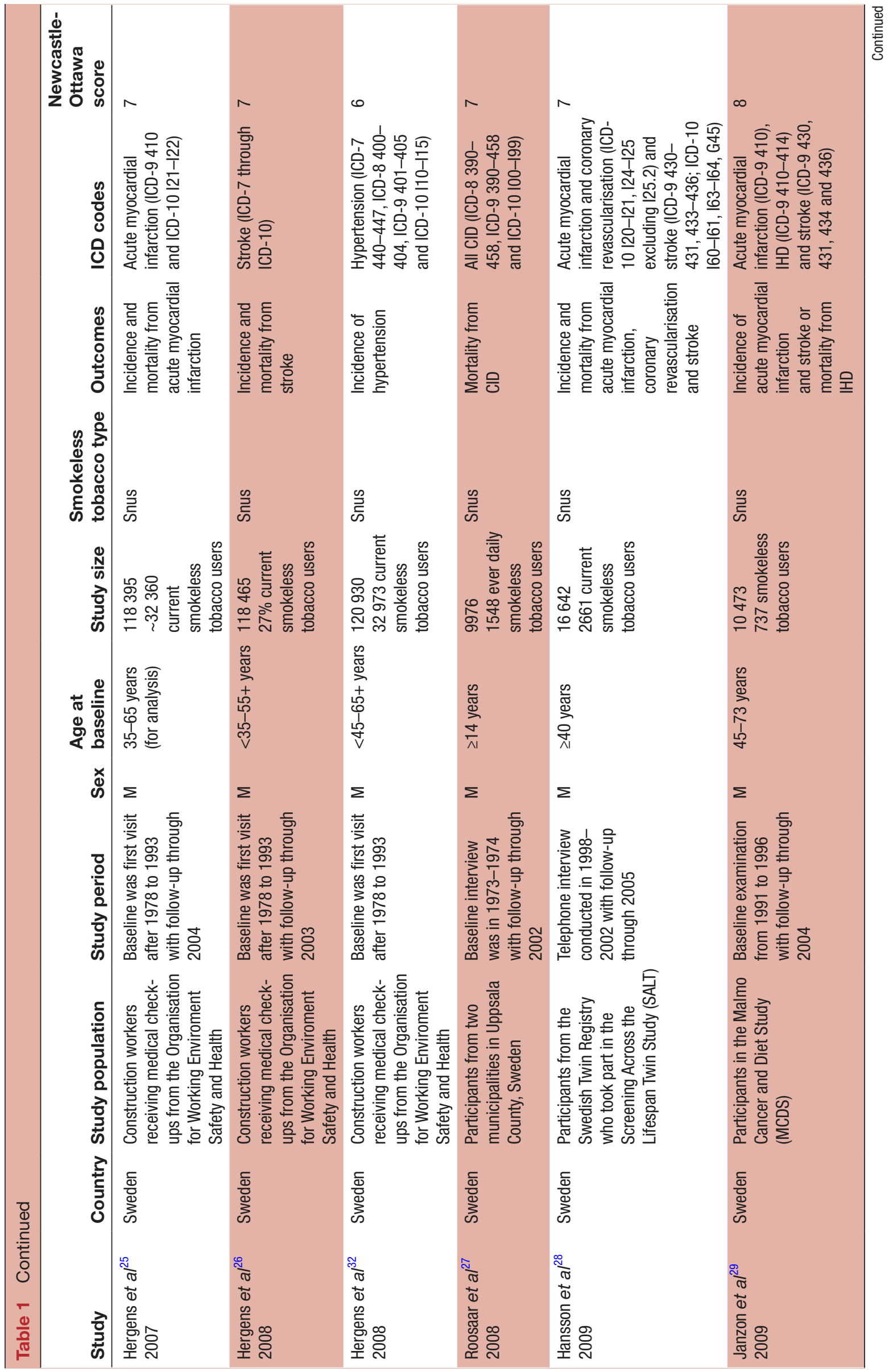




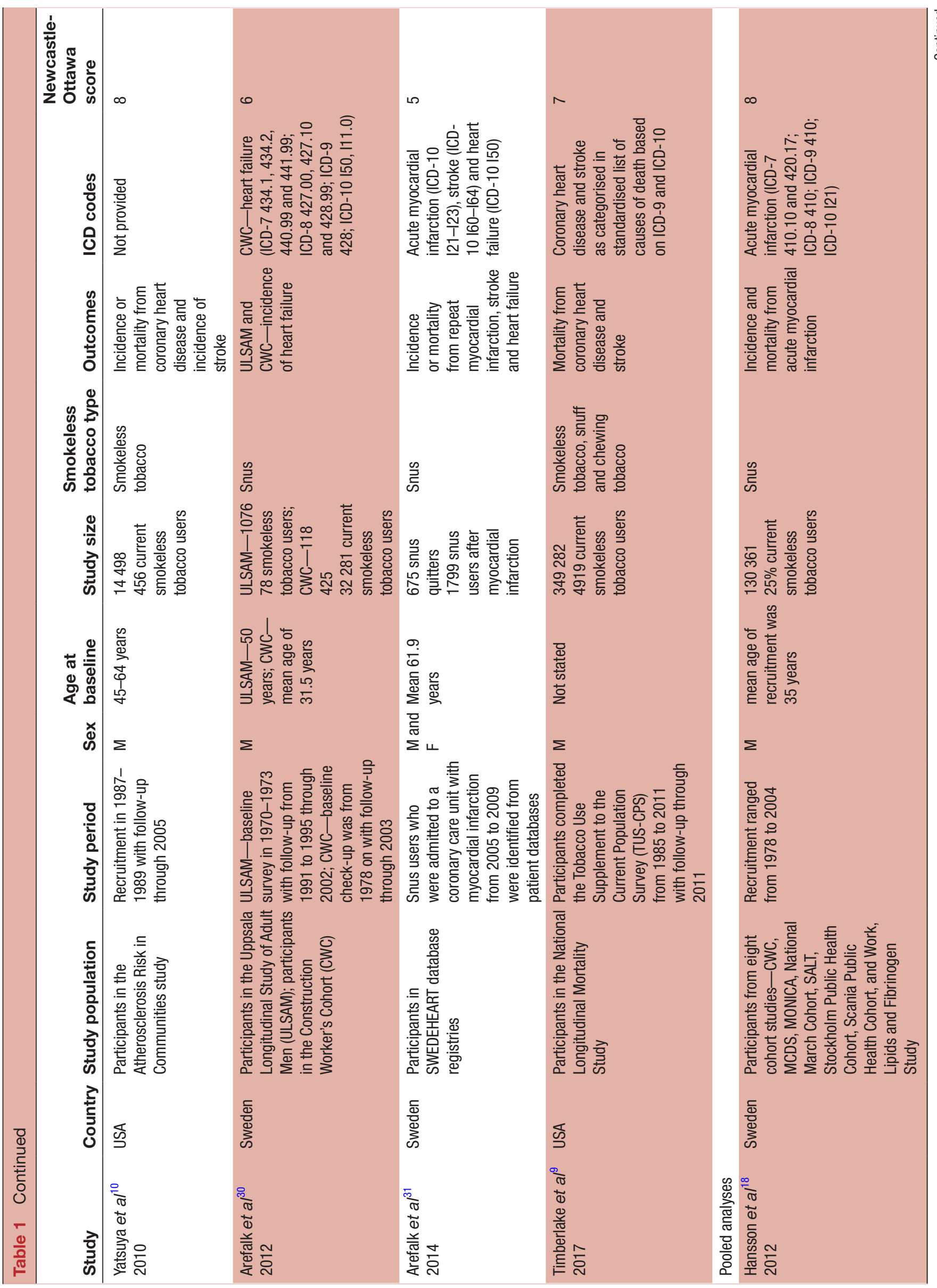




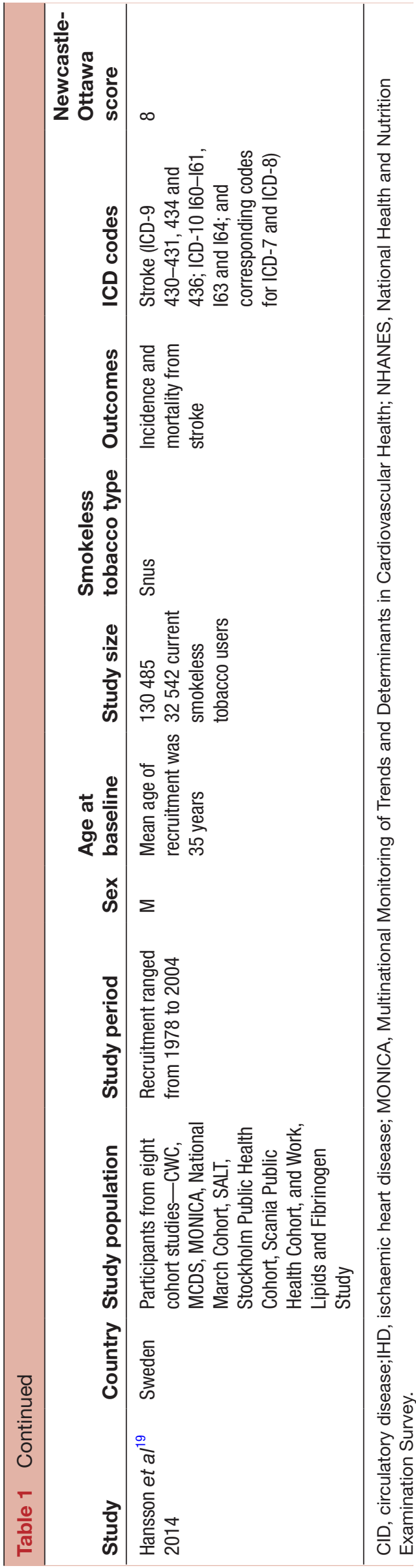

to have lower levels of the aldehyde acrolein than several commonly sold US traditional smokeless tobacco products, ${ }^{41}$ and acrolein is known to have toxic effects after ingestion and to cause cardiovascular damage through various mechanisms including oxidative stress and endothelial dysfunction. ${ }^{45}$ Swedish snus has also generally been found to have lower levels of toxic metals such as arsenic, cadmium and lead ${ }^{46}$ that have been linked to cardiovascular disease, ${ }^{47}$ although US moist snuff products have generally been found to meet the GothiaTek standard for most metals other than cadmium. ${ }^{42}$

The effect of nicotine on the circulatory system is complicated, but particularly relevant to the observed associations between smokeless tobacco use and circulatory disease risk. Studies have consistently found that cigarette smoking causes circulatory damage and disease through numerous pathways including oxidative injury, endothelial damage, enhanced thrombosis and chronic inflammation. ${ }^{48}$ Even so, the American Heart Association has issued a policy statement that concluded that nicotine may contribute to the effects of smoking on cardiovascular health but that other constituents in cigarette smoke appear to have a much more important effect. ${ }^{49}$ Research has found that nicotine, regardless of its route of administration, can increase blood pressure and heart rate. ${ }^{48}$ A network meta-analysis of 21 randomised clinical trials involving nicotine replacement therapy (NRT) products found that NRT use was associated with increased risk of all cardiovascular events including less severe conditions such as heart palpitations (RR 2.29, 95\% CI 1.39 to 3.82 ) but not necessarily with increased risk for severe cardiovascular events such as myocardial infarction, stroke or death (RR 1.95, 95\% CI 0.264 .30$).^{50}$ US smokeless tobacco users have been found to have nicotine exposure levels that may exceed those of cigarette smokers, ${ }^{51}$ but nicotine absorption from cigarette smoke occurs much faster on average than from smokeless tobacco, ${ }^{52}$ which may cause greater damage to the circulatory system. ${ }^{49}$ Swedish snus products have been found to have total nicotine levels that may be lower than levels in US moist snuff products, even though free nicotine levels have been found to be comparable in US and Swedish products. ${ }^{41} 42$

As noted in the Methods section, we identified preliminary studies by two groups of researchers ${ }^{14-16}$ that we did not include in our review because they have yet to be published. Nilsson et $a l^{14}$ examined acute myocardial infarction and snus use in a study of 726 Swedish cases and 726 controls. They did not find an association in this study population, which is consistent with results from our meta-analysis of snus use and ischaemic heart disease in Swedish studies. Fisher et al from Altria Client Services ${ }^{15} 16$ have presented relative risk estimates in conference presentations for US smokeless tobacco users from NLMS and National Health Interview Survey linked mortality data. They reported mortality HRs that were adjusted for self-reported health status, which may be viewed as an intermediate variable in the causal pathway 


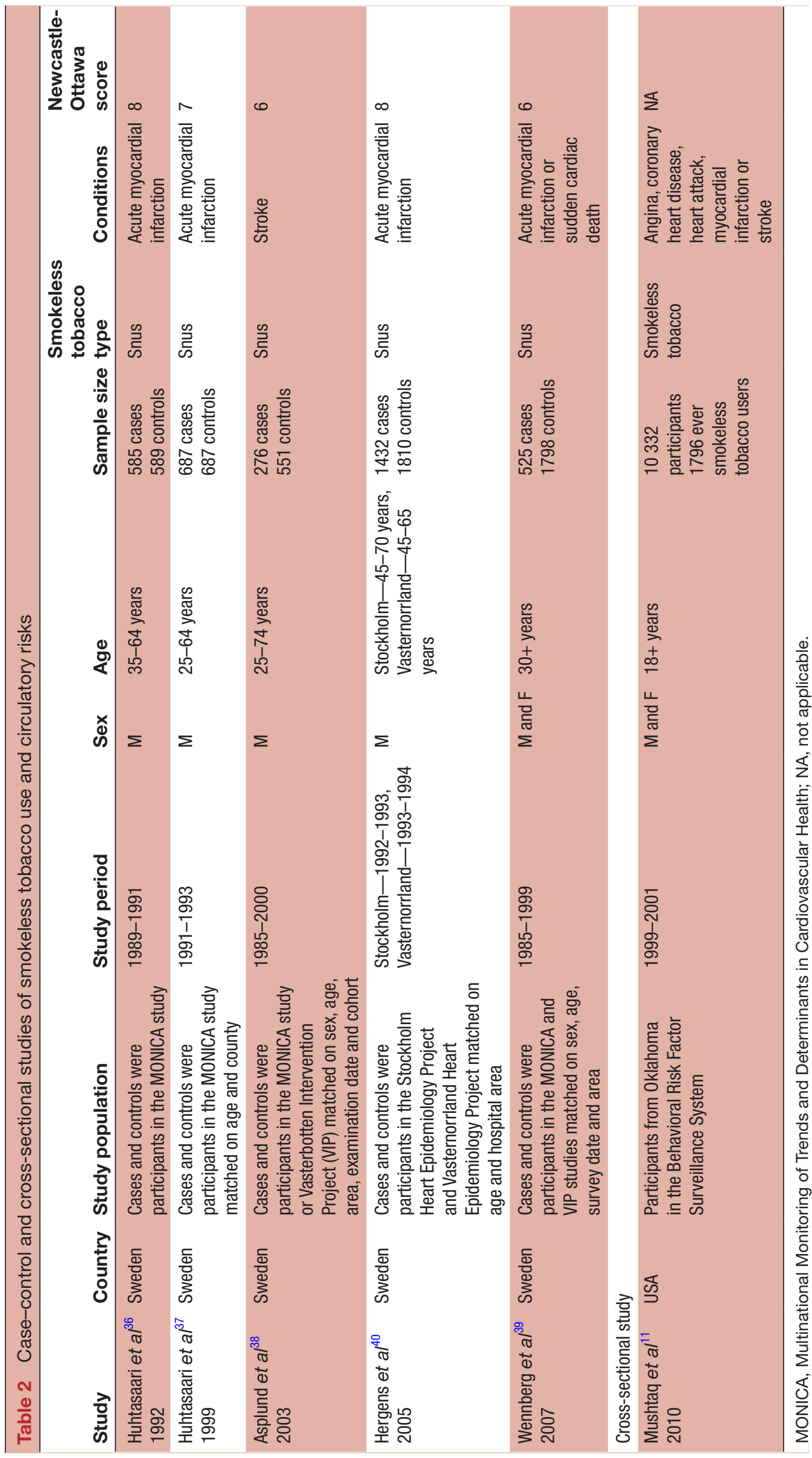




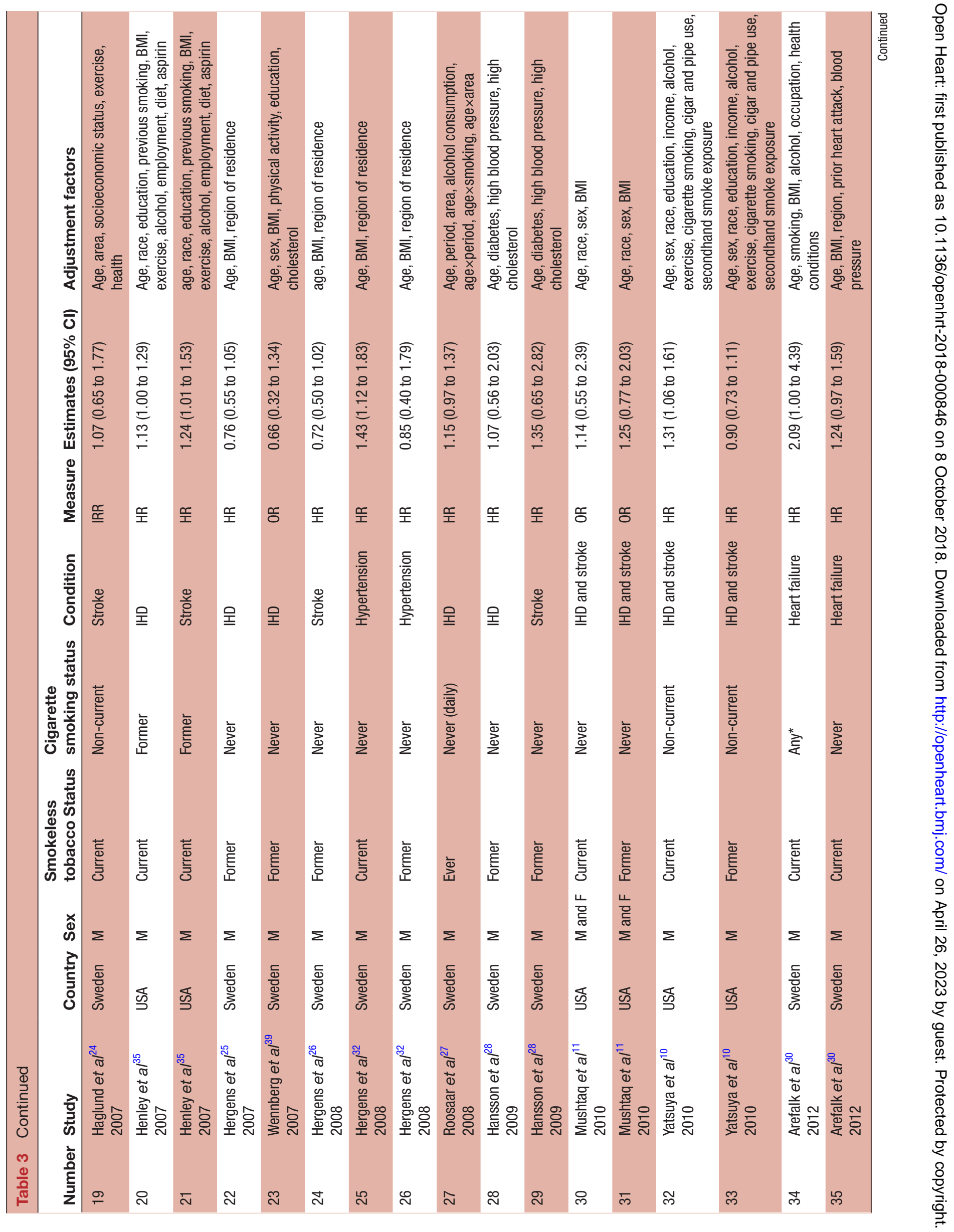




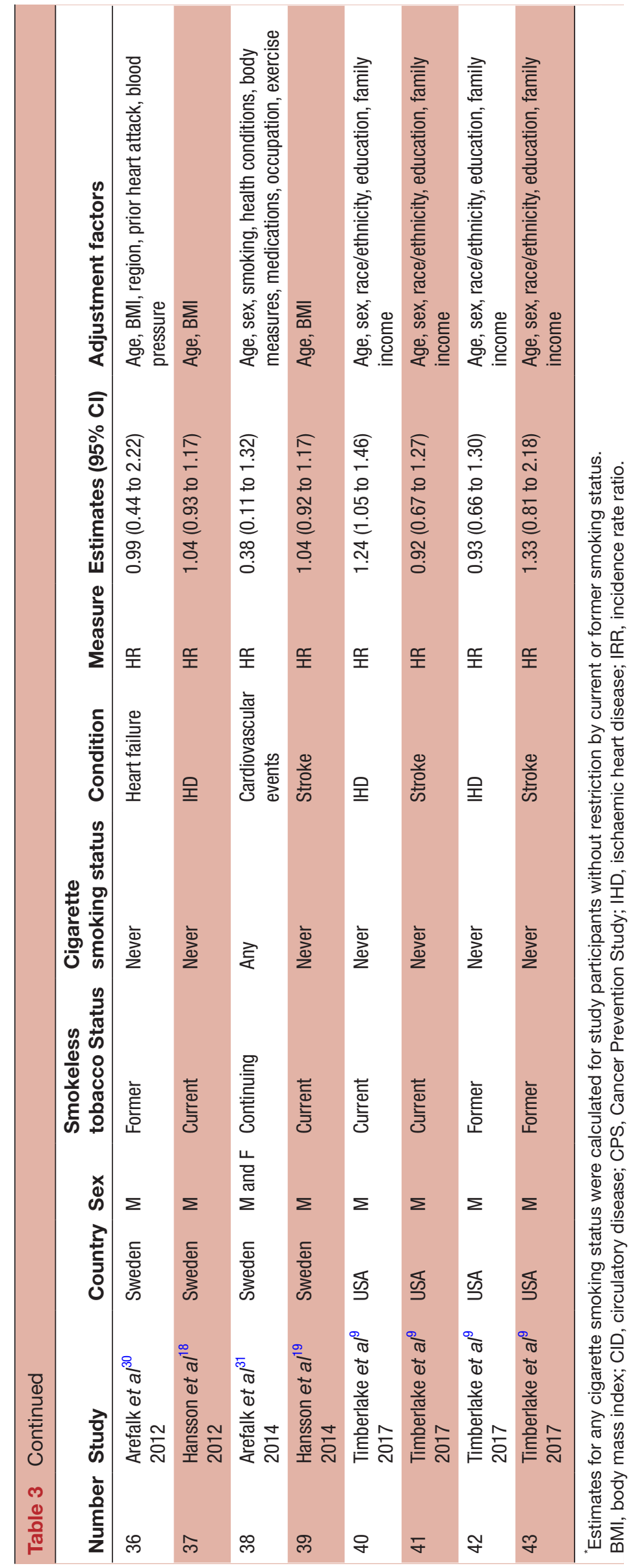




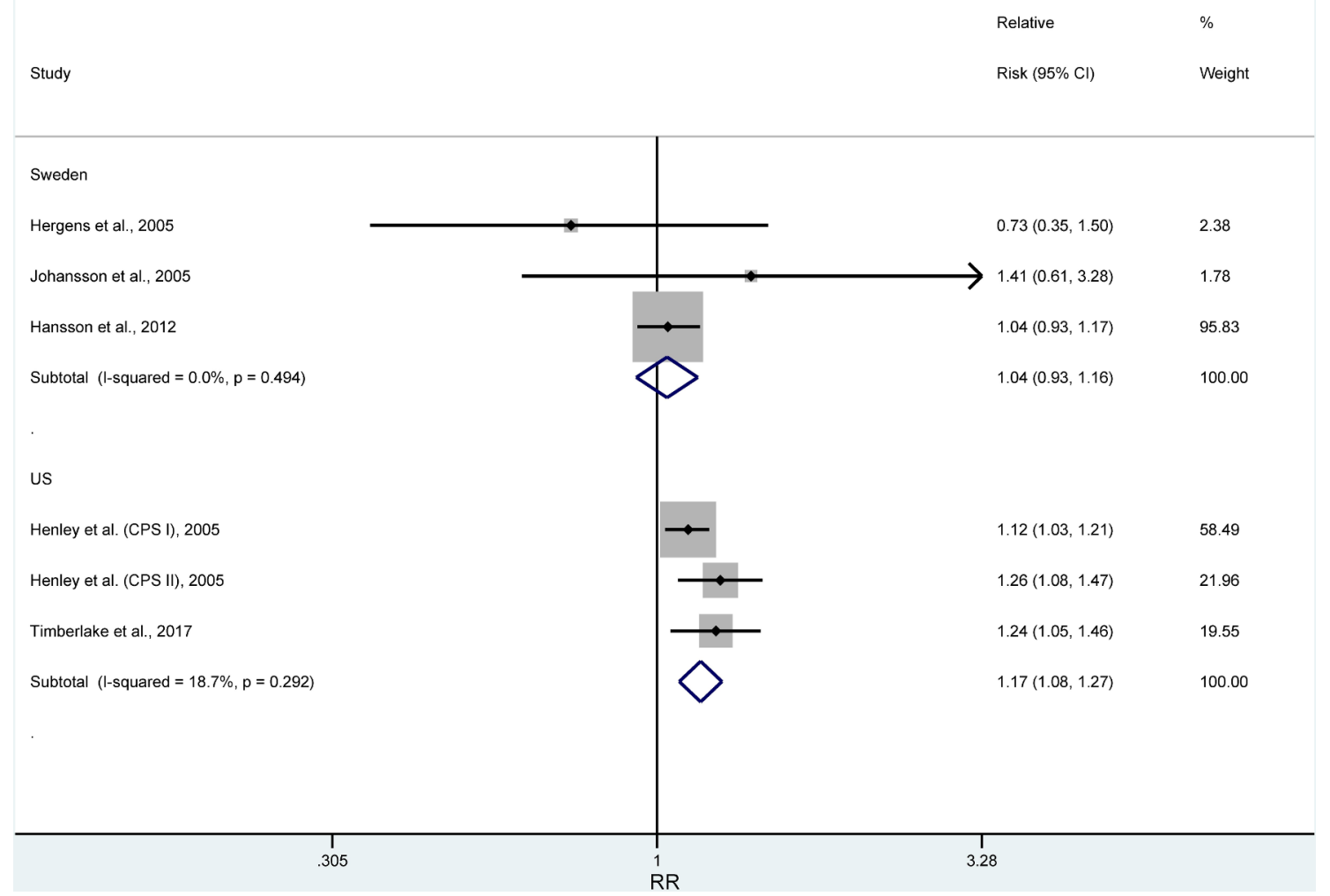

Figure 2 Meta-analysis of ischaemic heart disease risk estimates for current smokeless tobacco users in Sweden and the USA.

between exposure and outcome. Estimates in their presentations from NLMS data are lower than comparable estimates reported by Timberlake $e t$ al, which are included in this review.

This study has certain limitations. Smokeless tobacco use was usually self-reported by study participants, and information on use was often limited to current or ever use. In studies with linkage to mortality data such as the Cancer Prevention Studies (CPS) ${ }^{34}$ and NLMS, ${ }^{9}$ smokeless tobacco use was only reported in the baseline survey, and many current users at baseline may have quit use during the follow-up period. It has been shown using CPS II data that smoking cessation can bias relative risk estimates downward over an extended follow-up period. ${ }^{53}$ Study estimates also varied in the quantity and quality of adjustment for potential confounding risk factors, which may affect results. Some estimates by country and condition are based on a limited number of studies.

In conclusion, we have found that US smokeless tobacco users have increased risk of both heart disease and stroke, whereas we did not observe increased circulatory disease risk among Swedish smokeless tobacco users. Strengths of this analysis include the inclusion of additional, recent studies and estimates for former smokeless tobacco users and switchers from cigarettes to smokeless tobacco. Additional studies comparing constituent levels, use patterns and other characteristics of smokeless tobacco use across product types could help further strengthen our knowledge of the health risks of smokeless tobacco products.
Contributors BLR and CGC designed the review and developed the study protocol. MT designed the search strategy, and JTC and GMA conducted the literature review. BLR conducted the analysis and wrote the draft manuscript. All of the coauthors reviewed the manuscript and provided critical input.

Funding Funding for this project was provided by the Center for Tobacco Products, US Food and Drug Administration.

Disclaimer This publication represents the views of the authors and does not represent FDA/CTP position or policy.

Competing interests None declared.

Patient consent Not required.

Provenance and peer review Not commissioned; externally peer reviewed. Data sharing statement There are no additional data available.

Open access This is an open access article distributed in accordance with the Creative Commons Attribution Non Commercial (CC BY-NC 4.0) license, which permits others to distribute, remix, adapt, build upon this work non-commercially, and license their derivative works on different terms, provided the original work is properly cited, appropriate credit is given, any changes made indicated, and the use is non-commercial. See: http://creativecommons.org/licenses/by-nc/4.0/

Correction notice This article has been corrected since it published Online First. There were some instances of redundant texts (instructions from the authors) which have been removed now.

\section{REFERENCES}

1. National Cancer Institute and Centers for Disease Control and Prevention. Smokeless tobacco and public health: a global perspective. Bethesda, Md, 2014.

2. Lee PN. Circulatory disease and smokeless tobacco in Western populations: a review of the evidence. Int J Epidemiol 2007;36:789-804.

3. Boffetta P, Straif K. Use of smokeless tobacco and risk of myocardial infarction and stroke: systematic review with meta-analysis. BMJ 2009;339:b3060. 
Table 4 Meta-analyses of circulatory risks for smokeless tobacco users

\begin{tabular}{|c|c|c|c|c|c|c|}
\hline Country & Condition & $\begin{array}{l}\text { Smokeless } \\
\text { tobacco } \\
\text { status }\end{array}$ & $\begin{array}{l}\text { Cigarette } \\
\text { smoking } \\
\text { status* }^{*}\end{array}$ & $\begin{array}{l}\text { Number of study } \\
\text { estimates (estimate } \\
\text { numberst) }\end{array}$ & $\begin{array}{l}\text { Relative risk } \\
(95 \% \mathrm{Cl})\end{array}$ & $\begin{array}{l}\text { Measures of } \\
\text { heterogeneity }\end{array}$ \\
\hline \multirow[t]{14}{*}{ Sweden } & \multirow[t]{3}{*}{ Ischaemic heart disease } & Current & Never & $\mathrm{n}=3(15,17,37)$ & $1.04(0.93$ to 1.16$)$ & $p=0.494 I^{2}=0.0 \%$ \\
\hline & & Current & Any & $\mathrm{n}=4(15,17,18,37)$ & 0.99 (0.85 to 1.16$)$ & $p=\left.0.345\right|^{2}=9.7 \%$ \\
\hline & & Former & Never & $\mathrm{n}=5(1,16,22,23,28)$ & 0.85 (0.66 to 1.08) & $p=\left.0.609\right|^{2}=0.0 \%$ \\
\hline & \multirow[t]{3}{*}{ Stroke } & Current & Never & $\mathrm{n}=1$ (39) & 1.04 (0.92 to 1.17$)$ & - \\
\hline & & Current & Any & $\mathrm{n}=2(19,39)$ & $1.04(0.93$ to 1.17$)$ & $p=0.914 I^{2}=0.0 \%$ \\
\hline & & Former & Never & $\mathrm{n}=2(24,29)$ & $0.91(0.50$ to 1.64$)$ & $p=0.131 I^{2}=56.2 \%$ \\
\hline & \multicolumn{6}{|l|}{ Other circulatory disease } \\
\hline & \multirow[t]{2}{*}{ Heart failure } & Current & Any & $\mathrm{n}=2(34,35)$ & $1.43(0.91$ to 2.24$)$ & $p=0.190 I^{2}=41.9 \%$ \\
\hline & & Former & Never & $\mathrm{n}=1(36)$ & 0.99 (0.44 to 2.22) & - \\
\hline & \multirow[t]{2}{*}{ Hypertension } & Current & Never & $\mathrm{n}=1(25)$ & $1.43(1.12$ to 1.83$)$ & - \\
\hline & & Former & Never & $\mathrm{n}=1(26)$ & 0.85 (0.40 to 1.79$)$ & - \\
\hline & All circulatory disease & Ever & Never & $\mathrm{n}=1(27)$ & 1.15 (0.97 to 1.37 ) & - \\
\hline & \multicolumn{6}{|c|}{ Among users with previous myocardial infarction ('quitters' vs 'continuers') } \\
\hline & Cardiovascular events & Current & Any & $n=1(38)$ & 0.38 (0.11 to 1.32$)$ & - \\
\hline \multirow[t]{16}{*}{ US } & \multirow[t]{3}{*}{ Ischaemic heart disease } & Current & Never & $\mathrm{n}=3(6,9,40)$ & 1.17 (1.09 to 1.27$)$ & $p=0.292 \mathrm{I}^{2}=18.7 \%$ \\
\hline & & Current/ever & Never & $\mathrm{n}=5(2,3,6,9,40)$ & 1.18 (1.06 to 1.31$)$ & $p=\left.0.167\right|^{2}=38.2 \%$ \\
\hline & & Former & Never & $\mathrm{n}=2(12,42)$ & $0.80(0.61$ to 1.05$)$ & $p=0.220 I^{2}=33.7 \%$ \\
\hline & \multirow[t]{3}{*}{ Stroke } & Current & Never & $\mathrm{n}=3(7,10,41)$ & 1.28 (1.01 to 1.62$)$ & $p=0.028 I^{2}=72.0 \%$ \\
\hline & & Current/ever & Never & $\mathrm{n}=5(4,5,7,10,41)$ & $1.25(1.00$ to 1.55$)$ & $p=\left.0.066\right|^{2}=54.6 \%$ \\
\hline & & Former & Never & $\mathrm{n}=2(13,43)$ & 1.25 (0.93 to 1.69) & $p=\left.0.766\right|^{2}=0.0 \%$ \\
\hline & \multicolumn{6}{|l|}{ Other circulatory disease } \\
\hline & $\begin{array}{l}\text { Circulatory disease excluding } \\
\text { ischaemic heart disease and } \\
\text { stroke }\end{array}$ & Current & Never & $\mathrm{n}=2(8,11)$ & $1.06(0.93$ to 1.20$)$ & $p=\left.0.902\right|^{2}=0.0 \%$ \\
\hline & \multicolumn{6}{|l|}{ All circulatory disease } \\
\hline & \multirow{2}{*}{$\begin{array}{l}\text { Ischaemic heart disease and } \\
\text { stroke }\end{array}$} & Current & Never & $\mathrm{n}=1(30)$ & 1.14 (0.55 to 2.39$)$ & - \\
\hline & & Former & Never & $\mathrm{n}=1(31)$ & 1.25 (0.77 to 2.03) & - \\
\hline & \multirow[t]{2}{*}{$\begin{array}{l}\text { Ischaemic heart disease and } \\
\text { stroke }\end{array}$} & Current & $\begin{array}{l}\text { Non-current } \\
\text { (adjusted) }\end{array}$ & $\mathrm{n}=1(32)$ & 1.31 (1.06 to 1.61) & - \\
\hline & & Former & $\begin{array}{l}\text { Non-current } \\
\text { (adjusted) }\end{array}$ & $\mathrm{n}=1(33)$ & $0.90(0.73$ to 1.11$)$ & - \\
\hline & \multicolumn{6}{|c|}{ Among former cigarette smokers ('switchers') } \\
\hline & Ischaemic heart disease & Current & Former & $\mathrm{n}=1(20)$ & $1.13(1.00$ to 1.29$)$ & - \\
\hline & Stroke & Current & Former & $\mathrm{n}=1(21)$ & 1.24 (1.01 to 1.53$)$ & - \\
\hline
\end{tabular}

"Meta-analyses of studies with any smoking status include all study estimates for that condition and smokeless tobacco use status regardless of cigarette smoking status in individual studies. Meta-analyses of studies with non-current smoking status include estimates from studies that excluded current but not former smokers.

†Study estimate numbers are from table 3.

4. Zhang LN, Yang YM, Xu ZR, et al. Chewing substances with or without tobacco and risk of cardiovascular disease in Asia: a metaanalysis. J Zhejiang Univ Sci B 2010;11:681-9.

5. Siddiqi K, Shah S, Abbas SM, et al. Global burden of disease due to smokeless tobacco consumption in adults: analysis of data from 113 countries. BMC Med 2015;13:194.

6. Vidyasagaran AL, Siddiqi K, Kanaan M. Use of smokeless tobacco and risk of cardiovascular disease: a systematic review and metaanalysis. Eur J Prev Cardiol 2016;23:1970-81.

7. Sinha DN, Suliankatchi RA, Gupta PC, et al. Global burden of allcause and cause-specific mortality due to smokeless tobacco use: systematic review and meta-analysis. Tob Control 2018;27:35-42.
8. Gupta R, Gupta S, Sharma S, et al. Risk of coronary heart disease among smokeless tobacco users: results of systematic review and meta-analysis of global data. Nicotine Tob Res 2018.

9. Timberlake DS, Nikitin D, Johnson NJ, et al. A longitudinal study of smokeless tobacco use and mortality in the United States. Int J Cancer 2017;141:264-70.

10. Yatsuya H, Folsom AR, ARIC Investigators. Risk of incident cardiovascular disease among users of smokeless tobacco in the Atherosclerosis Risk in Communities (ARIC) study. Am J Epidemiol 2010;172:600-5. 
11. Mushtaq N, Beebe LA, Thompson DM, et al. Smokeless tobacco and prevalence of cardiovascular disease. J Okla State Med Assoc 2010;103:539-44.

12. Stanfill SB, Connolly GN, Zhang L, et al. Global surveillance of ora tobacco products: total nicotine, unionised nicotine and tobaccospecific N-nitrosamines. Tob Control 2011;20:e2.

13. Moher D, Liberati A, Tetzlaff J, et al. Preferred reporting items for systematic reviews and meta-analyses: the PRISMA statement. J Clin Epidemiol 2009;62:1006-12.

14. Nilsson G, Rosenblad A, Leppert J. Use of Swedish moist snuff and myocardial infarction: a case-control study of 726 patients and 726 control subjects matched for sex and age. EuroPRevent, 2012.

15. Fisher M, Tan-Torres S, Sarkar M. Health risks associated with use of smokeless tobacco products: analysis of a nationally representative mortality data set. Annual meeting of the Society for Research on Nicotine and Tobacco, Chicago, IL, 2016.

16. Fisher M, Tan-Torres S, Sarkar M. Health risks associated with use of smokeless tobacco products: analysis of two nationally representative mortality data sets. Annual meeting of the Society for Research on Nicotine and Tobacco, Florence, Italy, 2017.

17. Wells GSB, O'Connell D, Peterson J, 2017. The Newcastle-Ottawa Scale (NOS) for assessing the quality of nonrandomised studies in meta-analyses. Available from: http://www.ohri.ca/programs/clinical epidemiology/oxford.asp

18. Hansson J, Galanti MR, Hergens MP, et al. Use of snus and acute myocardial infarction: pooled analysis of eight prospective observational studies. Eur J Epidemiol 2012;27:771-9.

19. Hansson J, Galanti MR, Hergens MP, et al. Snus (Swedish smokeless tobacco) use and risk of stroke: pooled analyses of incidence and survival. J Intern Med 2014;276:87-95.

20. Arefalk G, Hergens MP, Ingelsson E, et al. Smokeless tobacco (snus) and risk of heart failure in two Swedish cohorts: PP.1.06. J Hypertens 2010;28:e48-e49.

21. Teo KK, Ounpuu S, Hawken S, et al. Tobacco use and risk of myocardial infarction in 52 countries in the INTERHEART study: a case-control study. Lancet 2006;368:647-58.

22. Bolinder G, Alfredsson L, Englund A, et al. Smokeless tobacco use and increased cardiovascular mortality among Swedish construction workers. Am J Public Health 1994:84:399-404.

23. Johansson SE, Sundquist K, Qvist J, et al. Smokeless tobacco and coronary heart disease: a 12-year follow-up study. Eur J Cardiovasc Prev Rehabil 2005;12:387-92.

24. Haglund B, Eliasson M, Stenbeck M, et al. Is moist snuff use associated with excess risk of IHD or stroke? A longitudinal followup of snuff users in Sweden. Scand J Public Health 2007;35:618-22.

25. Hergens MP, Alfredsson L, Bolinder G, et al. Long-term use of Swedish moist snuff and the risk of myocardial infarction amongst men. J Intern Med 2007;262:351-9.

26. Hergens MP, Lambe M, Pershagen G, et al. Smokeless tobacco and the risk of stroke. Epidemiology 2008;19:794-9.

27. Roosaar A, Johansson AL, Sandborgh-Englund G, et al. Cancer and mortality among users and nonusers of snus. Int $J$ Cancer 2008;123:168-73.

28. Hansson J, Pedersen NL, Galanti MR, et al. Use of snus and risk for cardiovascular disease: results from the Swedish Twin Registry. J Intern Med 2009;265:717-24.

29. Janzon E, Hedblad B. Swedish snuff and incidence of cardiovascular disease. A population-based cohort study. BMC Cardiovasc Disord 2009;9:21.

30. Arefalk G, Hergens MP, Ingelsson E, et al. Smokeless tobacco (snus) and risk of heart failure: results from two Swedish cohorts. Eur J Prev Cardiol 2012;19:1120-7.

31. Arefalk G, Hambraeus K, Lind L, et al. Discontinuation of smokeless tobacco and mortality risk after myocardial infarction. Circulation 2014;130:325-32.
32. Hergens MP, Lambe M, Pershagen G, et al. Risk of hypertension amongst Swedish male snuff users: a prospective study. J Intern Med 2008;264:187-94.

33. Accortt NA, Waterbor JW, Beall C, et al. Chronic disease mortality in a cohort of smokeless tobacco users. Am J Epidemiol 2002;156:730-7.

34. Henley SJ, Thun MJ, Connell C, et al. Two large prospective studies of mortality among men who use snuff or chewing tobacco (United States). Cancer Causes Control 2005;16:347-58.

35. Henley SJ, Connell CJ, Richter P, et al. Tobacco-related disease mortality among men who switched from cigarettes to spit tobacco. Tob Control 2007;16:22-8.

36. Huhtasaari F, Asplund K, Lundberg V, et al. Tobacco and myocardial infarction: is snuff less dangerous than cigarettes? BMJ 1992;305:1252-6.

37. Huhtasaari F, Lundberg V, Eliasson M, et al. Smokeless tobacco as a possible risk factor for myocardial infarction: a population-based study in middle-aged men. J Am Coll Cardiol 1999;34:1784-90.

38. Asplund K, Nasic S, Janlert U, et al. Smokeless tobacco as a possible risk factor for stroke in men: a nested case-control study. Stroke 2003;34:1754-9.

39. Wennberg P, Eliasson M, Hallmans G, et al. The risk of myocardial infarction and sudden cardiac death amongst snuff users with or without a previous history of smoking. J Intern Med 2007;262:360-7.

40. Hergens MP, Ahlbom A, Andersson T, et al. Swedish moist snuff and myocardial infarction among men. Epidemiology 2005;16:12-16.

41. Stepanov I, Jensen J, Hatsukami D, et al. New and traditional smokeless tobacco: comparison of toxicant and carcinogen levels. Nicotine Tob Res 2008;10:1773-82.

42. Borgerding MF, Bodnar JA, Curtin GM, et al. The chemical composition of smokeless tobacco: a survey of products sold in the United States in 2006 and 2007. Regul Toxicol Pharmacol 2012;64:367-87.

43. Pappas RS, Stanfill SB, Watson $\mathrm{CH}$, et al. Analysis of toxic metals in commercial moist snuff and Alaskan iqmik. J Anal Toxicol 2008;32:281-91.

44. Rutqvist LE, Curvall M, Hassler T, et al. Swedish snus and the GothiaTek® standard. Harm Reduct J 2011;8:11.

45. Henning RJ, Johnson GT, Coyle JP, et al. Acrolein can cause cardiovascular disease: a review. Cardiovasc Toxicol 2017; 17:227-36

46. Stepanov I, Hatsukami D. Call to Establish constituent standards for smokeless tobacco products. Tob Regul Sci 2016;2:9-30.

47. Solenkova NV, Newman JD, Berger JS, et al. Metal pollutants and cardiovascular disease: mechanisms and consequences of exposure. Am Heart J 2014;168:812-22.

48. Benowitz NL, Burbank AD. Cardiovascular toxicity of nicotine: implications for electronic cigarette use. Trends Cardiovasc Med 2016;26:515-23

49. Piano MR, Benowitz NL, Fitzgerald GA, et al. Impact of smokeless tobacco products on cardiovascular disease: implications for policy, prevention, and treatment: a policy statement from the American Heart Association. Circulation 2010;122:1520-44.

50. Mills EJ, Thorlund K, Eapen S, et al. Cardiovascular events associated with smoking cessation pharmacotherapies: a network meta-analysis. Circulation 2014;129:28-41.

51. Rostron BL, Chang CM, van Bemmel DM, et al. Nicotine and toxicant exposure among U.S. smokeless tobacco users: results from 1999 to 2012 National Health and Nutrition Examination Survey Data. Cancer Epidemiol Biomarkers Prev 2015;24:1829-37.

52. Benowitz NL, Porchet $\mathrm{H}$, Sheiner L, et al. Nicotine absorption and cardiovascular effects with smokeless tobacco use: comparison with cigarettes and nicotine gum. Clin Pharmacol Ther 1988;44:23-8.

53. Taylor DH, Hasselblad V, Henley SJ, et al. Benefits of smoking cessation for longevity. Am J Public Health 2002;92:990-6. 